Original Research Paper

\title{
Information Contents of Short Selling Restriction and Stock Lending and Borrowing Transactions
}

\author{
${ }^{1}$ Yeongsuk Cho and ${ }^{2}$ Youngsik Kwak \\ ${ }^{1}$ College of Business Administration, Mokpo National University, \\ 1666 Youngsan-ro, Muan-gun, Jeonnam, Korea 58554, Korea \\ ${ }^{2}$ Department of Accounting, Economics and Finance, \\ Delaware State University, 1200 North DuPont Highway, Dover, DE 19901, USA
}

\author{
Article history \\ Received: 16-09-2017 \\ Revised: 27-09-2017 \\ Accepted: 26-10-2017 \\ Corresponding Author: \\ Youngsik Kwak \\ Department of Accounting, \\ Economics and Finance, \\ Delaware State University, \\ 1200 North DuPont Highway, \\ Dover, DE 19901 \\ Tel: 302-857-6900 \\ Email: ykwak@desu.edu
}

\begin{abstract}
This study focuses on the distinctive incident in which Stock Lending and Borrowing (SLB) transaction and short selling grew continuously even during the wavering period of the Korea Composite Stock Price Index (KOSPI) in the Korea Exchange (KRX) market. The authors analyze the information contents of SLB and short selling on KOSPI financial stocks. The financial stocks were freed from short selling ban on November 14, 2013, after being banned for more than five years following the global financial crisis in 2008. Employing the event study methodology, the authors also analyze the differences between stock market returns before and after the short selling ban. The results of this study show that the concentrated group including high levels of SLB and short selling were characterized by the higher Abnormal Return (AR) with negative effect than the comparative group after the occurrence of short sales. The results also discover that SLB and short selling transactions provide the market with significant information contents. The information effect of SLB and short selling is consistent over time, but is stronger when the transactions are more concentrated. Finally, the results reveal that the short selling has the most considerable influence on the stock market.
\end{abstract}

Keywords: Stock Lending and Borrowing, Short Selling, Information Contents, Event Study, Korea Exchange Market, Abnormal Return, Cumulative Abnormal Return

\section{Introduction}

The Korea Stock Composite Index (KOSPI) has not broken out of the box pattern of 1,800 2,100p during six years in the Korea Exchange (KRX) stock market since 2010. The index is in a stagnant condition, while repeating fluctuation. Despite stagnation in the market, SLB and short selling have steadily increased. Both its trading volume and value have doubled in four years since 2010. This boom continues in the market. Furthermore, the Korean hedge funds were launched in December 2011. Following the launch, Korean institutional investors have increasingly participated in SLB and short selling, which had been utilized mostly by foreign investors in the past. While the short selling of financial stocks had been restricted since the 2008 global financial crisis, the restriction was lifted on November 14, 2013 (Financial Services Commission, www.fsc.go.kr). As the restriction on short selling of financial stocks was released and SLB was gradually boosted, both SLB and short selling can be increasingly utilized in various investment strategies.

During the global financial crisis of 2008, temporary market stabilization schemes such as restriction of naked short selling, restriction of short selling of financial stocks, reinforcement of official announcement of short selling and etc. Those measures were announced before and after the end of September 2008 in 27 countries among 49 countries where short selling was previously permitted. In the KRX, short selling of every stock was banned after October 1, 2008 and was allowed again except financial stocks eight months later on June 1, 2009. Meanwhile, even when short selling was restricted in the KRX market, SLB had gradually increased and the SLB of financial stocks was steadily practiced. Since then, the market signaling effect of the SLB and short selling has been a continued academic discussion (Song, 2006; Lee, 2009; Kim, 2010; Lee et al., 2010; Eom et al., 2011; Cho and Hwang, 2014; etc.) 
Short selling is the practice of selling stocks which are not currently owned or borrowed, anticipating price decline. In the KRX, for the purpose of stock market stabilization and price formation, naked short selling is banned. Therefore, the procedure to borrow stocks through SLB in order to execute short selling is indispensable. Due to the cyclic nature of processes (borrowing - short selling - repurchasing - redemption) where each step is closely related to the other, it is necessary to systematically analyze the relationship between SLB, short selling and the information effect on the stock market. However, in the case of the KRX, only a few studies have investigated the relationship and thus presented only limited results. For example, Eom et al. (2011) argued that short selling by foreign investors is not related to stock prices. Hwang and Cho (2012) showed that SLB has a significant effect of increasing both volatility and liquidity in the stock market. In another study, Cho and Hwang (2014) reported that the information effect of SLB is emerging in the Korean stock market. On the other hand, research in the foreign stock markets have been conducted around short selling only (Jones and Lamont, 2002; Nagel, 2005; Henry and McKenzie, 2006; Bris et al., 2007; Boehmer et al., 2008; Harris et al., 2013 and etc.).

Thus, this study analyzes the relationship between SLB, short selling and the information effect, which emerged in the KRX for 6 months before and after the allowance of short selling (from September 1, 2013 to February 28, 2014), focusing on financial stocks where the short selling ban was lifted after five years on November 14, 2013. Specifically, this study analyzes how SLB and short selling are related to each other and how they affect investors' responses and the efficiency of stock prices. It has been reported that the Korean hedge fund earned a comparatively high return by employing a long-short strategy which largely utilizes SLB and short selling. Thus, the results of this study will provide significant suggestions for fund investment companies, market participants and policy makers.

This study differs from previous studies in two aspects. First, while most previous studies analyzed either the effect of short selling or the effect of lending and borrowing on the market in total, this study examines the effect of market response before and after the lifting of short selling ban by applying the event study methodology. Second, this study examines the direct and indirect effects of variables related to SLB and short selling on stock prices, and thus analyzes the interactive relationship and its information effect. This study focuses on the distinctive incident in which there was continuous growth of SLB transaction and short selling even during the wavering period of the KOSPI in the KRX market.

\section{Recent Trend of SLB and Short Selling and Previous Studies}

The graph on the left in Fig. 1 shows that the proportion of short selling transactions in KOSPI is steadily increasing. The proportion was around $1.5 \%$ in early 2010 , over $3 \%$ in the first half of 2011 and reached up to $4 \%$ in 2013 . It has more than doubled over three years.

It has turned out that the influence of short selling is considerably expanding. The chart on the right in Fig. 1 shows that the average daily trading volume of SLB in the KRX market was about 10 million shares in early 2010 and is recently 15 20 million shares. This means that its trading volume has increased about $50 \%$. The outstanding quantity of SLB was $1 \%$ of the total shares at the time and is now $2 \%$ which indicates double growth. Its balance amount was $\$ 1.5$ billion and jumped to $\$ 3.91$ trillion at the end of February 2014 which shows a growth rate of $260 \%$.

SLB began in the KRX in September 1996, approximately $90 \%$ of SLB transactions were carried out by foreign investors. Its trading volume and balance are continually increasing. In the meantime, Korean hedge funds were introduced in late 2011, which pursue absolute returns through diverse investment strategies such as long-short strategies. Accordingly, domestic investment and securities firms have been steadily participating in SLB transactions, occupying about $15 \%$ to $20 \%$. Meanwhile, $80 \%$ of total brokerages of SLB are occupied by the Korea Securities Depository (KSD) and the other $20 \%$ by securities firms and individual stock companies. The Korea Financial Investment Association (KOFIA) has collected and announced all domestic SLB transactions according to the regulations of Capital Market Act since October 2008.

Even though SLB can be used with derivative products and for the establishment of ETF, ELS and ELW, it is mainly associated with covered short selling. In the sense that short selling is a negative signal to stock prices, it has a large impact on investment psychology. Therefore, the KRX announces the transaction and balance of short selling of each stock every day.

Table 1 shows the trading volume of SLB announced by the KSD which occupies most of the brokerage of SLB. In the last five years, trading volume of SLB was $\$ 65.6$ billion at the trough in 2009 and rapidly increased $51.4 \%$, worth $\$ 99.3$ billion. Subsequently, it steadily increased 2.2 times over five years which is worth $\$ 143.9$ billion. It may be possible that because the restriction of short selling which was enforced during the time of global financial crisis in 2008 was lifted, Korean hedge funds were introduced at the end of 2011 and domestic prime brokers were vitalized to support the hedge funds.

Meanwhile, as for the stock borrowing through the KSD, 80.6\% ( $\$ 115.3$ billion) was occupied by foreign 
investors and 19.4\% (\$27.7 billion) by Korean investors. As for stock lending, $77.5 \% \quad(\$ 110.7$ billion $)$ was occupied by foreign investors and $22.5 \%$ ( $\$ 32.2$ billion) by Korean investors. The recent trend also shows that the domestic trading proportion of SLB has gradually increased. Specifically, the domestic trading proportion of stock borrowing was no more than $7.0 \%$ in 2009 , but it increased $19.4 \%$ in 2013. As for the domestic stock lending, it increased from 7.75 in 2009 to $22.5 \%$ in 2013.

Figure 2 shows the total balance of SLB in the KRX market and the proportion trend of SLB of financial firms (KOFIA, www. Kofia.or.kr). It is observed that even during the time when short selling in financial firms was restricted, SLB was continually practiced. However, redemption was intensively practiced during the short period of year end and new borrowing was contracted in the first week of the next year so that it increased again to the previous level.

Table 2 shows the performance comparison of SLB and short selling of fifteen stocks which represent financial firms for the three months before and after
November 14, 2013 when the short selling of financial stocks was allowed after five years and two months. After the short selling of financial stocks was permitted, the proportion of SLB of financial stocks increased $23.1 \%$ (trading value was $12.9 \%$ ) and the trading proportion of short selling was $12.1 \%$ (trading value was $7.7 \%$ ). Also, the trading proportion of the top fifteen financial stocks in comparison to the other stocks increased from 2.7 to $4.4 \%(+64.2 \%)$ and the trading value increased from 5.3 to $6.8 \%(+28.3 \%)$.

This rapid increase shows the opposite trend observed in November and December 2013 when the total balance of SLB stagnated or considerably decreased in the year end. It is observed that particularly during the period from November 14 until November 30, when short selling was permitted after 5 years, the cumulative proportion of short selling was $17 \%$ of the total trading volume of short selling, valued at $9.8 \%$. This indicates that a considerable amount of short selling was practiced during that period, which in turn, remarkably affected the market.

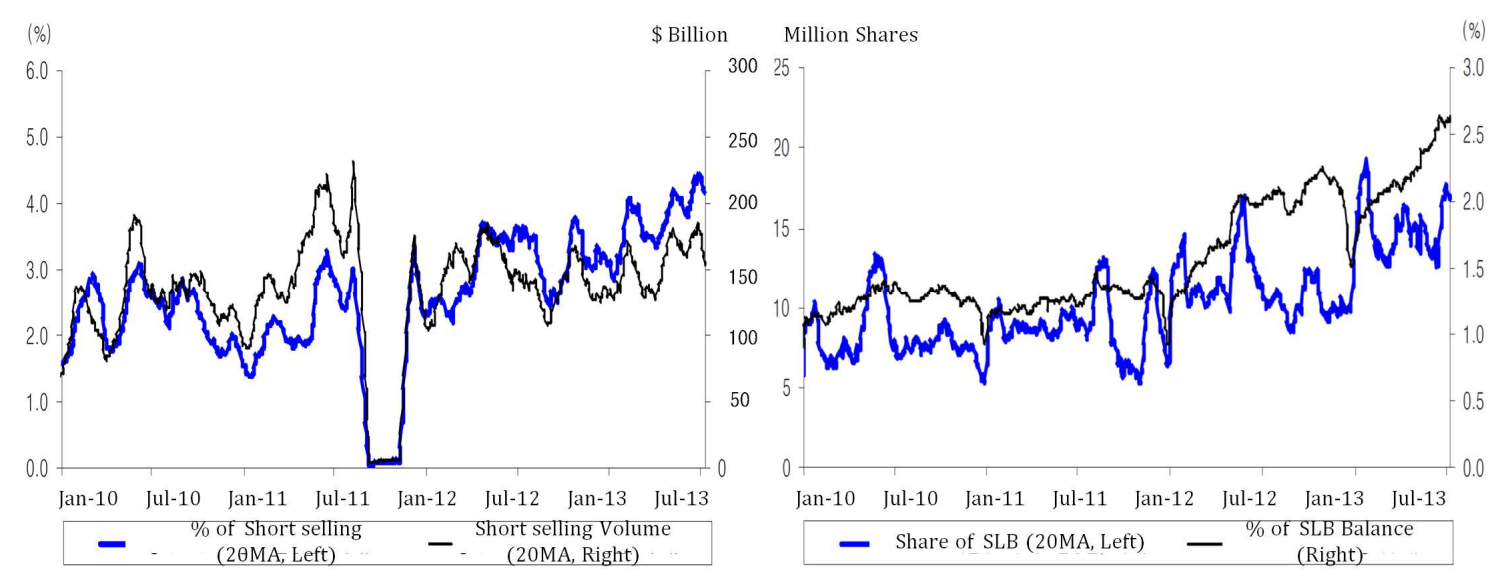

Fig. 1. Trend of short selling and SLB in KOSPI, *Source: Re-quoted from samsung securities, investment information issue (July 15, 2103)

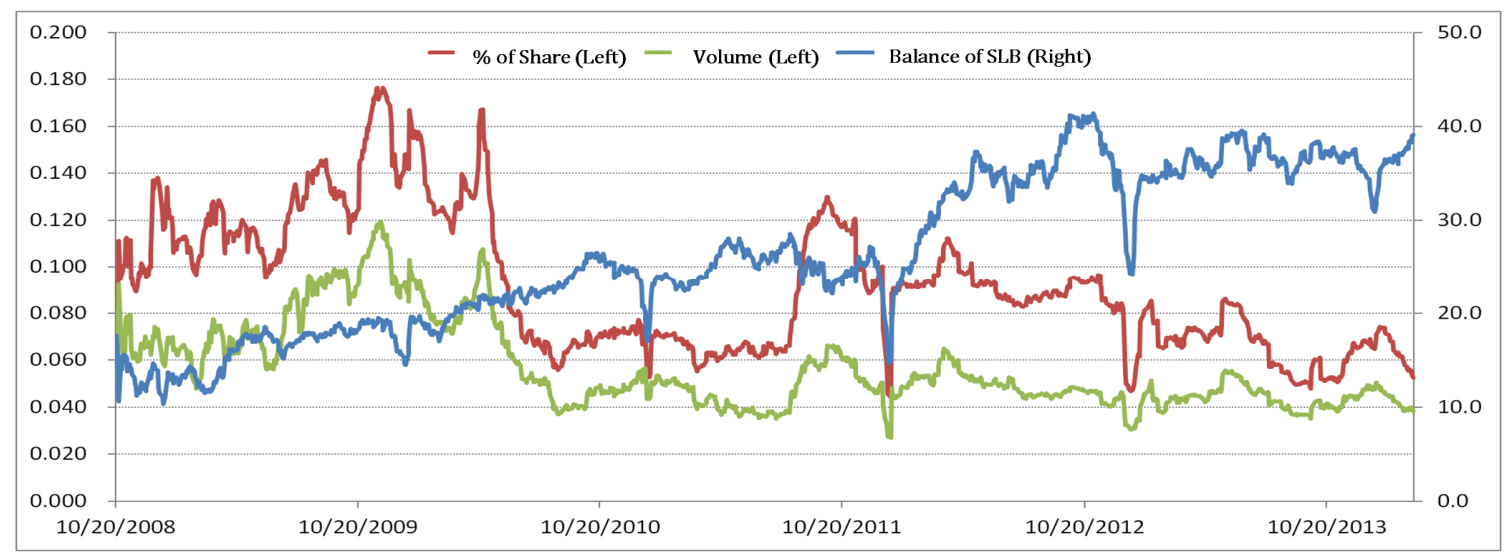

Fig. 2. Trend of SLB balance and SLB in financial firms in KOSPI (Oct. 20, $2008 \sim$ Feb. 28, 2014, daily), *Source: Korea Financial Investment Association (KOFIA), www.kofia.or.kr 
Table 1. SLB Transactions in the last five years (Unit: One million stocks, \$1 million)

\begin{tabular}{|c|c|c|c|c|c|c|}
\hline \multirow[b]{2}{*}{ Year } & \multicolumn{2}{|l|}{ Value } & \multicolumn{2}{|c|}{ Volume } & \multicolumn{2}{|l|}{ Balance } \\
\hline & Amount & Rate & Stocks & Rate & Stocks & Rate \\
\hline 2009 & 65,613 & - & 1,577 & - & 102,579 & - \\
\hline 2010 & 99,328 & $51.4 \%$ & 1,849 & $17.3 \%$ & 107,324 & $4.6 \%$ \\
\hline 2011 & 112,689 & $13.5 \%$ & 1,914 & $3.5 \%$ & 114,078 & $6.3 \%$ \\
\hline 2012 & 126,867 & $12.6 \%$ & 2,340 & $22.3 \%$ & 191,061 & $67.5 \%$ \\
\hline 2013 & 142,901 & $12.6 \%$ & 2,974 & $27.1 \%$ & 244,936 & $28.2 \%$ \\
\hline
\end{tabular}

* Source: Korea Securities Depository (KSD), www.ksd.or.kr, Yearly data arrangement

Table 2. Proportional change of short selling in financial firms (15 firms) for three months before and after the ban was lifted (March 14, 2013) (Unit: \%)

\begin{tabular}{|c|c|c|c|c|c|c|}
\hline \multirow[b]{2}{*}{ Period } & \multicolumn{2}{|c|}{ Proportion of SLB } & \multicolumn{2}{|c|}{$\begin{array}{l}\text { Proportion of short selling } \\
\text { of top } 15 \text { firms }\end{array}$} & \multicolumn{2}{|c|}{ Total financial firms } \\
\hline & Stocks & Trading volume & Volume & Trading volume & Volume & Trading volume \\
\hline $\begin{array}{l}\text { Before (A) } \\
(2013, \text { Sep. 1 } \\
\text { 2013, Nov. 13) }\end{array}$ & 5.2 & 3.9 & $0.3^{*}$ & $0.3^{*}$ & 2.7 & 5.3 \\
\hline $\begin{array}{l}\text { After (B) } \\
\text { (2013, Nov. 14 } \\
\text { 2014, Feb. 29) }\end{array}$ & 6.5 & 4.4 & 12.1 & 7.7 & 4.4 & 6.8 \\
\hline Rate $(\mathrm{B} / \mathrm{A})$ & 23.1 & 12.9 & - & - & 64.2 & 28.3 \\
\hline
\end{tabular}

\section{Methodology}

\section{Sample and Data Collection}

The following sample data was established to analyze specific information effect: What effect the increasing phenomena of SLB and short selling, which appeared after the lifting the short selling ban on financial stocks, have on the stock market and the rate of return of individual stocks.

This study targets 51 firms (bank: 9, securities: 23, insurance: 13 , other financial: 5, credit card: 1), which were selected out of 67 financial firms that were traded at the end of 2013 in the KRX stock market, excluding 17 preferred stocks. The survey was conducted for six months before and after the permission of short selling, from September 1, 2013 until February 28, 2014. To analyze the information effect of SLB and short selling, this study divided the target firms into two groups: The focus group (Group A) which is comprised of the stock price of the top 15 firms of SLB and short selling, and the comparative group (Group B) which is comprised of the stock price of 15 bottom firms (with no or least SLB and short selling).

Financial firms are subdivided into bank, securities and insurance company. The characteristic and business environment of each subsample was taken into consideration so that 15 top and bottom firms are comprised of five banks, five securities and five insurances companies, respectively. Then, additional analyses were conducted into the respective subsample company. Data related to SLB utilized in this study were obtained from data announced on the homepage of KOFIA (www.kofia.or.kr). Data related to short selling and stock price, trading volume and return rates were utilized from the homepage of the KRX (www.krx.co.kr). The statistical analysis was executed with the E-views program.

\section{Research Model}

The trend of return rate before and after the permission of short selling of financial firms (November 14, 2013) is analyzed through the Event Study method. Abnormal return was estimated by using the market return model, as this method measures an excess return, reflecting the relationship that return of individual stock is affected by the market factor. The equation to deduct the Abnormal Return (AR) and Cumulative Abnormal Return (CAR) of each stock is as follows. First, stock return rate and market index return rate were used during a period of 120 days from 130 days before the restriction release of short selling of sample companies until the base date or 10 days before the release and then return parameters $\alpha_{j}$ and $\beta_{j}$ are estimated with the least squares method. Then, with these $\alpha_{j}$ and $\beta_{j}$ utilized, the normally expected return rate $\left(\alpha_{j}+\beta_{j} . R_{m, t}\right)$ during the analysis period was attained, which was subtracted from the actual return $\left(R_{i, t}\right)$ so that the AR rate $\left(A r_{i, t}\right)$ was calculated as follows:

$A R_{i, t}=R_{i, t}-\left(a_{j}+\beta_{j} \cdot R_{m, t}\right)$ 
Based upon the AR rate which was calculated for each company, the average abnormal return $\left(A A R_{t}\right)$ of the total portfolio is calculated then, the $C A R_{t}$ for the period from the event period until a particular time.

$$
\begin{aligned}
& A A R_{t}=\left(\frac{1}{N}\right) \sum_{i=1}^{N} A R_{i, t} \\
& C A R_{t}=\sum_{t=1}^{N} A A R_{t}
\end{aligned}
$$

The difference of the AR rates between the focus group (Group A) where SLB and short selling is vigorously traded and the comparative group (Group B) where SLB and short selling hardly or seldom occur can be identified based upon the result of analysis.

\section{Regression Analysis}

The inter-relationship of SLB and short selling and the information effect are specifically analyzed. The SLB is comprised of two phases: stock borrowing transaction, which is to borrow stock initially to sell stocks which were not owned by the seller. And stock redemption, which is to return the stocks to the lender before the end of the contract period or under the contract condition. In addition, the content of short selling is also analyzed. In general, it has been known that the stocks which are borrowed through the stock borrowing transaction are utilized for short selling, program trading related to derivative products and redemption for borrowed stocks. About $30 \%$ of SLB which were traded through initial stock borrowing transactions go on to short selling within the same day. Meanwhile, the performance of SLB and short selling are announced every day on the homepages of the KOFIA and KRX, respectively. Therefore, the information effect on which this information has on investors in the market should be analyzed. For this analysis, the trade performance of SLB and short selling are divided into daily and weekly performances and the associate variables were chosen as follows.

\section{Associate Variables}

- $\quad$ Lending and Borrowing Rate (LBR) = Number of shares borrowed for the last five days/outstanding shares

- Short Selling Rate $(\mathrm{SSR})=$ Number of shares shorted for the last five days / outstanding shares

- $\quad$ Total Lending Rate (TLR) = Outstanding quantity of the stock borrowing / outstanding shares

- Short Selling/(Total Lending and Borrowing) $(\mathrm{SS} / \mathrm{TLB})=$ Number of shares shorted for the last five days/outstanding quantity of the stock borrowing

- Redemption Rate $($ RDR $)=$ Number of shares redeemed for the last five days / outstanding quantity of the stock borrowing (the previous day)

- $\quad$ Rate of Returned Daily (RRD) = Number of shares redeemed / trading volume

- Abnormal Return Rate (AR) Total of abnormal returns rate $\left(A r_{i . t}\right)$ for five days after time $t$.

To analyze the specific information effect through interactive influences based upon these chosen variables, four hypotheses are established:

Hypothesis 1: There is a significant and positive relationship between SLB transaction and short selling

Hypothesis 2: There is a significant and negative relationship between SLB transaction and the price of earnings ratio

Hypothesis 3: There is a significant and negative relationship between short selling and the price earnings ratio

Hypothesis 4: There is a significant and positive relationship between redemption transaction and the price earnings ratio

\section{Statistical Analysis}

\section{Basic Statistics}

Table 3 shows the basic statistics of associate variables.

\section{Trend of the Price Earnings Ratio after the Restriction Release of Short Selling}

Figure 3 shows the AAR and CAR of the short selling focus group during the period from 7 days before (D-7) until 30 days after (D+30) November 14, 2013 (D), when the restriction of short selling on financial firms was released. Here, it was clearly demonstrated that the event of lifting of the short selling ban had a considerable effect on the price of financial stocks.

In other words, short selling of stocks that were borrowed through large-scale SLB from November 14,2013 (D-0), when the restriction of short selling was released until 2 days after $(\mathrm{D}+2)$, intensively occurred so that the AAR rapidly fell. Thus, a negative coordination effect was strongly made due to short selling, which means that it is significant at the $1 \%$ significance level. Subsequently, it was restored to a normal return rate eleven days after the event $(\mathrm{D}+11)$, showing about $1 \%$ of excess return rate twelve days after the event and $2 \sim 3 \%$ of CAR 24 days after the event.

Figure 4 shows the trend of the AAR and CAR of the comparative group where SLB and short selling hardly occur in spite of the restriction release of short 
selling. As shown in Fig. 4, the AAR and CAR of the comparative group are different from those of the focus group. The release of short selling ban had almost no effect on the AAR. On the contrary, the comparative group showed a negative CAR sixteen days after the event $(D+16)$ as opposed to the focus group, showing that the interest of investors was migrating to the focus group.

As a result of this analysis, it can be assessed that statistically, the release of short selling ban was a significant event and therefore has a significant effect on stock prices. In addition, it shows that while the occurrences of SLB and short selling had a significant effect on the stock market temporarily, the opposite phenomena (occurrence of excess return rate) can take place 24 days $(\mathrm{D}+24)$ after the trade date.

Figure 5 shows the results of the subsamples of the focus group of SLB. Here it was observed that the negative coordination effect which occurred after the release of short selling ban was discovered at all three subsamples respectively (AAR: Securities $-4.34 \%$, Bank $-1.00 \%$, Insurance $-0.24 \%$ ). Particularly, the largest effect was found in the securities firms. The effect was more intensive in the securities firms which was largely affected by the depression of the capital market than in the other fields. It was analyzed that the securities firms showed the highest negative AAR through intensive short selling of stocks which were borrowed by large-scale SLB, indicated four days of consecutive downward coordination and proved that it had the biggest impact of all three fields. It can be verified that the event of the release of short selling ban had a considerable effect on the market. This result assures that stocks with the high proportion of
SLB and short selling were more affected than others. Thus, it can be analyzed that the effect of SLB and short selling on the market is proportional to SLB and short sale trading volume.

Furthermore, the AR trend shows that it moved sequentially with one week (approximately 5 trading days) apart, securities stocks first followed by bank and insurance stocks. This is evaluated as the strategy of SLB and short selling manifested a return rate in the pattern of circulatory rally in the financial stocks right after the lift of short selling ban.

Table 4 shows the daily AAR and CAR of the focus group and the comparative group. Here, it was confirmed that in general, the AAR value has a statistically significant value. Particularly, the negative coordination effect which occurred right after the release of short selling ban on November 14 was significant at a $1 \%$ significance level, showing a statistically significant result at a $10 \%$ significance level at $\mathrm{D}+1$ and at a $5 \%$ significance level at $\mathrm{D}+2$.

\section{Information Effects of SLB and Short Selling}

Table 5 shows the results of regression analysis which was conducted to analyze the influence of variables associated with SLB and short selling. In conducting regression analysis, an appropriate control variable should be used to control an effect other than the variables. However, this study utilized daily data and therefore was not able to use a control variable such as EPS or asset size which are quarterly or yearly data. Thus, as a dependent variable, this study used the AR rate calculated with the Market Return Model to take market influence into consideration.

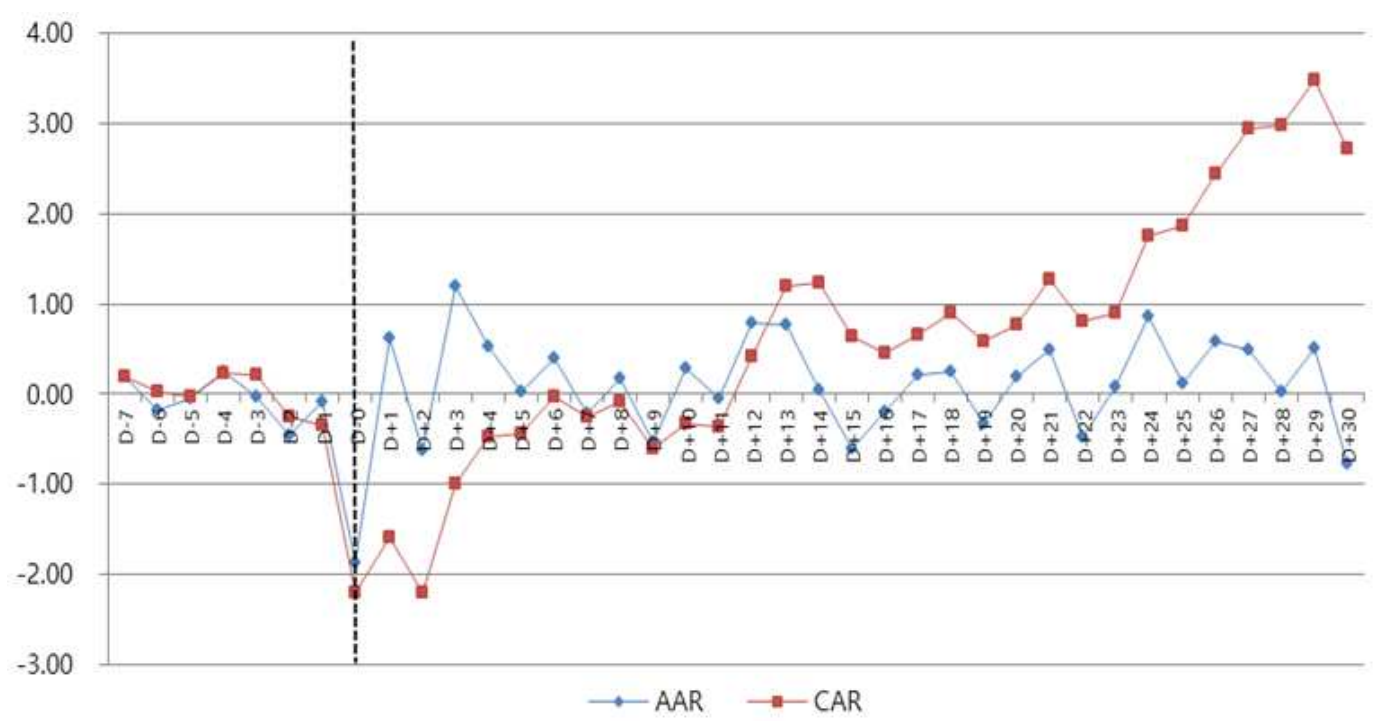

Fig. 3. Trend of the AAR and CAR of the Short Selling Focus Group 


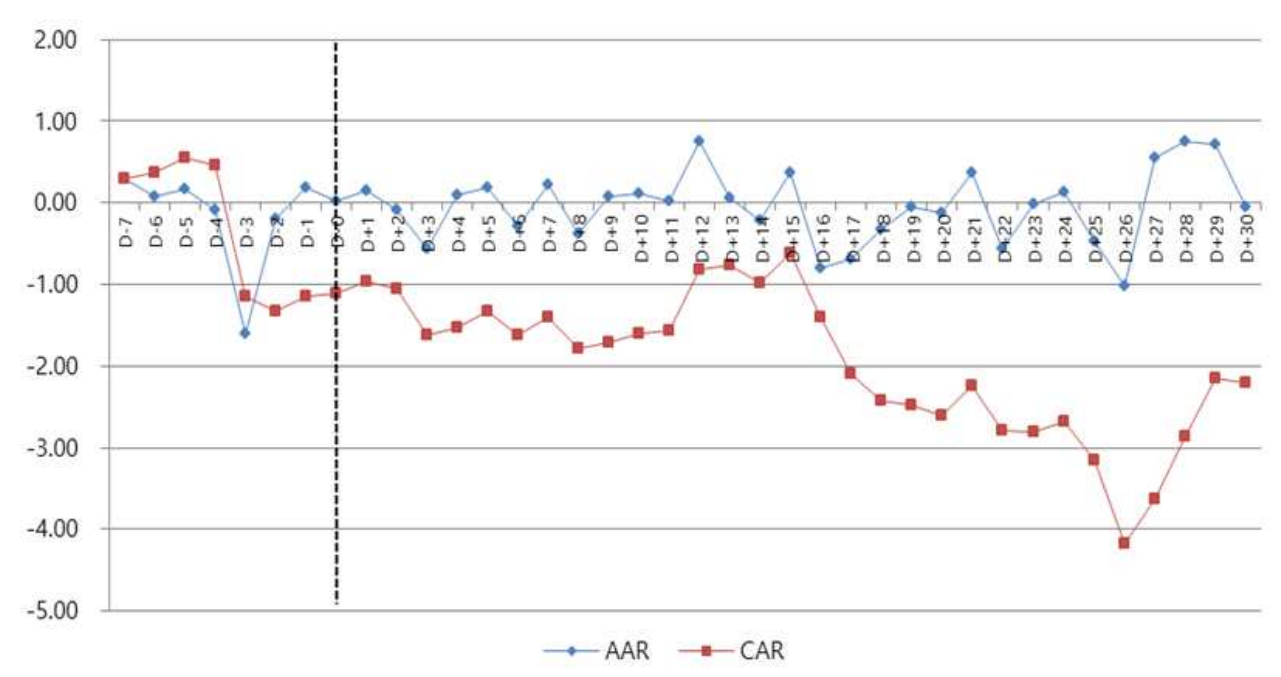

Fig. 4. Trend of AAR and CAR of Comparing Group

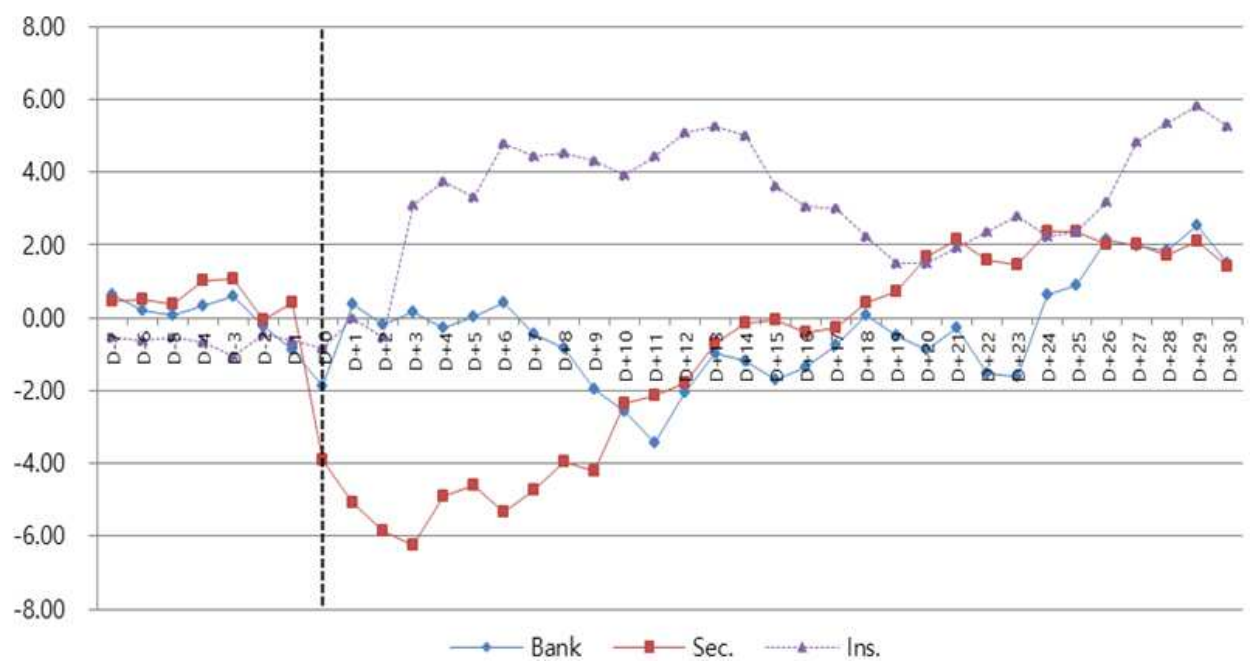

Fig. 5. Trend of CAR of Each Subdivided Field

Table 3. Basic statistics

\begin{tabular}{|c|c|c|c|c|c|c|c|}
\hline & $\mathrm{N}$ & Mean & Std. dev. & Maximum & Minimum & Skewness & Kurtosis \\
\hline Lending and Borrowing Rate (LBR) & 1785 & 0.0024 & 0.0054 & 0.0778 & 0 & 7.4157 & 78.1531 \\
\hline Short-Selling Rate (SSR) & 1785 & 0.0005 & 0.0010 & 0.0095 & 0 & 4.1944 & 25.3409 \\
\hline Redemption Rate (RDR) & 1785 & 0.0881 & 0.1241 & 1.8391 & 0 & 5.2851 & 53.0821 \\
\hline Total Lending Rate (TLR) & 1785 & 0.0249 & 0.0242 & 0.1374 & 0 & 2.1302 & 7.4388 \\
\hline $\begin{array}{l}\text { Short-Selling/ } \\
\text { (Total Lending and Borrowing) (SS/TLB) }\end{array}$ & 1785 & 0.0208 & 0.0372 & 0.2950 & 0 & 3.6648 & 19.5621 \\
\hline
\end{tabular}

The results of analysis with the target of the whole period regarding Hypothesis 1 show that the Lending and Borrowing Rate (LBR) and Total Lending Rate (TLR) had a positive effect on the Short Selling Rate (SSR) and were significant at the $1 \%$ significance level. It was shown that this influence was equally significant during the three periods including the whole period, the period after restriction release of short selling and the period of intensive occurrence. Then, it was indicated that LBR is more influential than TLR.

As a result of testing Hypothesis 2, it was found that LBR had a negative effect on AR and was significant at the $1 \%$ significance level. On the contrary, TLR had a positive effect and was significant at the $5 \%$ significance level. Meanwhile, SS/TLB proved to be insignificant statistically. 
Table 4. AAR and CAR during sample period

\begin{tabular}{|c|c|c|c|c|c|}
\hline \multirow[b]{2}{*}{ Date } & \multicolumn{2}{|c|}{ Focus group } & \multicolumn{2}{|c|}{ Comparative group } & \multirow[b]{2}{*}{ T-statistic } \\
\hline & AAR & CAR & AAR & CAR & \\
\hline $\mathrm{D}-7$ & 0.20 & 0.20 & 0.30 & 0.30 & 0.830 \\
\hline D-6 & -0.17 & 0.02 & 0.07 & 0.37 & -0.613 \\
\hline D-5 & -0.05 & -0.03 & 0.18 & 0.55 & -0.258 \\
\hline D-4 & 0.26 & 0.23 & -0.09 & 0.46 & 1.390 \\
\hline D-3 & -0.03 & 0.20 & -1.60 & -1.14 & -0.144 \\
\hline D-2 & -0.46 & -0.25 & -0.19 & -1.33 & $-1.695^{*}$ \\
\hline D-1 & -0.09 & -0.34 & 0.20 & -1.14 & -0.407 \\
\hline D-0 & -1.86 & -2.20 & 0.02 & -1.12 & $-3.509^{* * *}$ \\
\hline $\mathrm{D}+1$ & 0.62 & -1.58 & 0.15 & -0.97 & $1.727^{*}$ \\
\hline $\mathrm{D}+2$ & -0.62 & -2.19 & -0.10 & -1.06 & $-2.389^{* *}$ \\
\hline $\mathrm{D}+3$ & 1.20 & -0.99 & -0.56 & -1.62 & 1.319 \\
\hline $\mathrm{D}+4$ & 0.53 & -0.47 & 0.10 & -1.52 & 1.337 \\
\hline $\mathrm{D}+5$ & 0.04 & -0.43 & 0.19 & -1.33 & 0.186 \\
\hline $\mathrm{D}+6$ & 0.40 & -0.03 & -0.29 & -1.62 & 0.941 \\
\hline $\mathrm{D}+7$ & -0.22 & -0.25 & 0.22 & -1.41 & -0.760 \\
\hline $\mathrm{D}+8$ & 0.18 & -0.08 & -0.38 & -1.79 & $-2.112^{* *}$ \\
\hline $\mathrm{D}+9$ & -0.53 & -0.61 & 0.07 & -1.72 & $-1.654^{*}$ \\
\hline $\mathrm{D}+10$ & 0.29 & -0.32 & 0.11 & -1.60 & 0.706 \\
\hline $\mathrm{D}+11$ & -0.05 & -0.37 & 0.03 & -1.57 & -0.163 \\
\hline $\mathrm{D}+12$ & 0.79 & 0.42 & 0.75 & -0.82 & $3.109^{* * *}$ \\
\hline $\mathrm{D}+13$ & 0.77 & 1.19 & 0.06 & -0.77 & $2.396^{* *}$ \\
\hline$D+14$ & 0.04 & 1.24 & -0.21 & -0.98 & 0.207 \\
\hline $\mathrm{D}+15$ & -0.60 & 0.63 & 0.36 & -0.62 & $-2.112^{* *}$ \\
\hline$D+16$ & -0.19 & 0.45 & -0.79 & -1.41 & -0.601 \\
\hline $\mathrm{D}+17$ & 0.20 & 0.65 & -0.70 & -2.10 & 0.624 \\
\hline$D+18$ & 0.25 & 0.91 & -0.32 & -2.43 & 1.002 \\
\hline $\mathrm{D}+19$ & -0.33 & 0.58 & -0.05 & -2.48 & -1.503 \\
\hline $\mathrm{D}+20$ & 0.20 & 0.77 & -0.13 & -2.61 & 0.535 \\
\hline $\mathrm{D}+21$ & 0.49 & 1.27 & 0.37 & -2.24 & $1.991^{* *}$ \\
\hline $\mathrm{D}+22$ & -0.46 & 0.81 & -0.56 & -2.80 & -1.325 \\
\hline $\mathrm{D}+23$ & 0.08 & 0.89 & -0.02 & -2.81 & 0.248 \\
\hline $\mathrm{D}+24$ & 0.86 & 1.75 & 0.13 & -2.68 & $1.887^{*}$ \\
\hline $\mathrm{D}+25$ & 0.11 & 1.87 & -0.47 & -3.15 & 0.370 \\
\hline $\mathrm{D}+26$ & 0.58 & 2.44 & -1.03 & -4.17 & $2.281^{* *}$ \\
\hline $\mathrm{D}+27$ & 0.50 & 2.94 & 0.55 & -3.63 & 1.168 \\
\hline $\mathrm{D}+28$ & 0.03 & 2.97 & 0.76 & -2.86 & 0.127 \\
\hline$D+29$ & 0.52 & 3.48 & 0.72 & -2.15 & $2.782^{* * *}$ \\
\hline $\mathrm{D}+30$ & -0.77 & 2.72 & -0.06 & -2.20 & $-2.442^{* *}$ \\
\hline
\end{tabular}

Note) $*, * *, * *$ indicate significance level $10,5 \%$ and $1 \%$ respectively

Regarding Hypothesis 3, SSR had a strong negative effect on AR and was significant at the $1 \%$ significance level. Likewise, LBR had a negative effect on $A R$ at the $1 \%$ significance level. It is interpreted that SLB and short selling have a direct and strong, negative effect on stock price. Meanwhile, TLR and SS/TLB are analyzed to have a significant effect. Subsequently, regarding Hypothesis 4, RDR had a statistically low regression coefficient and was statistically insignificant.

Based on the result of analysis of the period after the release of short selling ban, regarding Hypothesis 1, both LBR and TLR had significant positive effects on SSR and were significant at the $1 \%$ significance level. While TLR and SS/TLB had positive effects on TLR of
Hypothesis 2, LBR had a negative effect and were significant at the $1 \%$ significance level. Regarding Hypothesis 3, LBR had a negative effect and SS/TLB had a positive effect and was significant at the $10 \%$ significance level. Meanwhile, SSR had a very strong negative effect and was significant at the $1 \%$ significance level. RDR of Hypothesis 4 proved to be insignificant.

Lastly, it was shown what effects SLB, short selling and redemption trading had on stock price during the period when they occurred intensively after the restriction release of short selling. Each effect was additionally analyzed. Here, associate variables were extracted and analyzed only if LBR was over $1 \%$, SSR was over $0.2 \%$ and RDR was over $20 \%$, respectively, for performances which occurred for the last five trade days. 
Table 5. Regression coefficient of each variable

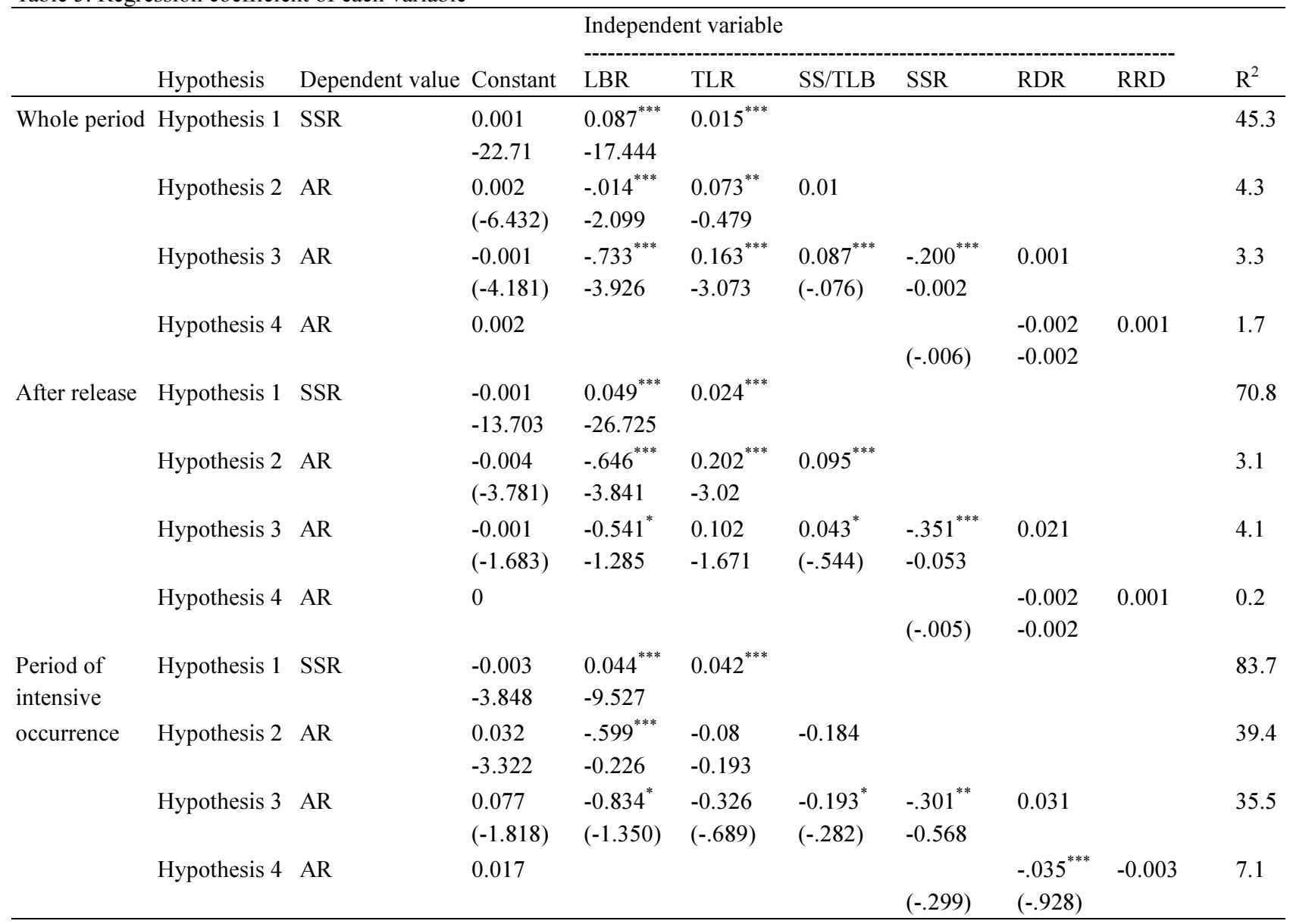

Note) $*, * *, * *$ means 10,5 and $1 \%$ significance level respectively

As a result of analysis of the intensive period, regarding Hypothesis 1, LBR and TLR had a significant positive effect on SSR at the 1\% significance level and regarding Hypothesis 2, LBR had a significant negative effect on AR at the $15 \%$ significance level. While TLR and SS/TLB showed a positive coefficient, it was insignificant statistically. It is evaluated that during the period when SLB and short selling intensively occurred, LBR had a more significant effect than other variables. Regarding Hypothesis 3, SSR had a very strong negative effect of AR and was significant at the $1 \%$ significance level. LBR and SS/TLB had a significant negative effect respectively. In addition, regarding Hypothesis 4, unlike the result of analysis of other periods, RDR had a negative effect on $\mathrm{AR}$ and was significant at the 5\% significance level. It is not interpreted that SLB led to a rising stock price, but that it showed the opposite tendency in the short term.

As shown in Table 6, the results of analysis can be summarized as follows. It was found that SLB and short selling provided the market with significant information effect. While SLB had a significant positive effect on short selling, SLB and short selling had a significant negative effect. Particularly, the influence of short selling was more significant than the other. However, the redemption trading had a significant negative effect on stock price, contrary to the hypothesis.

This finding can be interpreted as a result of the strategic movement of institutional investors who intensively utilize SLB. Redemption trading is generally more highly related to short selling in the short term than initial borrowing transaction and it occurs more frequently during periods of stock price decreases. Meanwhile, even stocks that reported a new high can practice short covering due to the danger of additional price increase and therefore, a situation takes place to have to redeem stocks. Thus, it can be interpreted that a redemption trading after stock price decline implies a shift of upward trend, while a stock redemption that occurs after stock price reported a new high can possibly show characteristics of additional increase of price.

In conclusion, it has been confirmed that institutional investors and professional investors who positively utilize short selling are borrowing stocks through SLB and practice short selling in order to promote return rate in terms of investment strategy. Moreover, it has been proved that after SLB and short selling intensively occur, stock price can decline in the short term. 
Table 6. Analysis result of influence of each variable

\begin{tabular}{lllll}
\hline Hypothesis & Independent variable & Dependent variable & Hypothesis influence & Result of substantial analysis \\
\hline Hypothesis1 & Stock borrowing & Short selling & + & + \\
Hypothesis2 & Stock borrowing & Stock price & - & - \\
Hypothesis3 & Short selling & Stock price & - & - \\
Hypothesis4 & Redemption & Stock price & + & - \\
\hline
\end{tabular}

\section{Conclusion and Implications}

This study observed the characteristic phenomena that the utilization of SLB and short selling continually increased, even during the period of stagnating price of KOSPI in the KRX and also analyzed the information effect.

For research data, this study selected fifteen stocks that practiced intensive SLB and short selling among financial firms, of which restriction of short selling was released on November 14, 2013, after five years and two months unlike other general firms. Then, this study analyzed the data for six months (from September 2013 to February 2014) in terms of stock prices, SLB and short selling. In addition, to analyze the information effect, this study selected fifteen stocks that practiced the least SLB and short selling among the same industry and established them as the comparative group. Using an event study, this study calculated the AAR and CAR that appeared before and after the restriction release of short selling. Then, this study analyzed differences between the focus group and the comparative group. Subsequently, to analyze the information effect of SLB and short selling, this study established associate variables and executed a regression analysis. The result of this study is summarized as follows.

First, the event study results show that the stocks intensively traded by SLB and short selling had a negative coordination effect after the short selling occurred, in contrast to other stocks. The results also show a positive effect after a certain period $(D+24)$.

Second, it was discovered that SLB and short selling provided the market with significant information effect. Specifically, SLB had a significant positive effect on short selling, furthermore SLB and short selling had a significant negative effect on the stock prices. Particularly, the influence of short selling was the most significant. However, it was found that redemption trading unlike other stocks had a significant negative effect on the stock prices.

Third, while the influence of these variables generally appeared consistently, it appeared more certain during the period when SLB and short selling intensively occurred. Particularly, it was confirmed that the short selling rate is a variable that had a direct and the largest effect on the stock prices.

The implication of this study is as follows. For naked short selling is restricted in the KRX, as well as in most stock markets around the world, SLB occurs in advance before short selling which appears due to the sell pressure of the stock market. Thus, it is crucial to thoroughly compare and analyze the information effect which is related to SLB and short selling before analyzing the influence of short selling or policy execution.

In addition, since SLB and short selling have important effect on stock prices, they are highly valuable investment strategy for increasing fund return rates. Then, the information of short selling should be announced more sufficiently and accurately in order to provide relevant investment information. Currently, the KRX announces only the volume of short selling that occurred the day before. This customary content of announcement needs to be supplemented. That is, the total outstanding short selling interests and balance on each stock should be announced.

One limitation of this study is that it did not utilize sufficient control variables. To clearly differentiate the effect of SLB from that of short selling, the influence of foreign selling and buying should be controlled, and the unsystematic risk that affects stock prices needs also be controlled. In addition, it is recommended that further study be undertaken into analyzing the effects of program trade, foreign straight purchase and foreign share ratio on stock prices.

\section{Acknowledgement}

The researchers gratefully acknowledge the Mokpo National University in Korea.

\section{Funding Information}

This study was supported by Research Funds of Mokpo National University in 2013.

\section{Author's Contributions}

Yeongsuk Cho: Contributed to the writing of the manuscript, designed and coordinated research plan and organized the study. Responsible for data collection and provided the qualitative research design and analysis. Reviewed and revision of the manuscript.

Youngsik Kwak: Contributed the data-analysis, interpreted data taking into account the unique characteristics of the research. Provided research findings, designed the research methodology reviewed and revision of the manuscript. 


\section{Ethics}

This article is original and contains unpublished material. The corresponding author confirms that the other author have read and approved the manuscript and no ethical issues involved.

\section{References}

Boehmer, E., M.C. Jones and X. Zhang, 2008. Which shorts are informed? J. Finance, 63: 491-527.

Bris, A., W.N. Guetzman and N. Zhu, 2007. Efficiency and the bear: Short sales and markets around the world. J. Finance, 62: 1029-1079.

Cho, Y.S. and S.W. Hwang, 2014. Information content of SLB transactions in Korea. Korean J. Financial Eng., 13: 147-171.

Eom, K.S., K.B. Bin and J.S. Kim, 2011. A study on effect and precedence of foreigner's short selling on stock price in the level of individual stock. Korean J. Financial Manage., 28: 139-187.

Financial Services Commission, Press release related to restriction of short selling. http://www.fsc.go.kr

Harris, L.E., E. Namvar and B. Phillips, 2013. Price inflation and wealth transfer during the 2008 SEC short-sale ban. J. Investment Manage, 11: 5-27.

Henry, T.O. and M. McKenzie, 2006. The impact of short selling on the price-volume relationship: Evidence from Hong Kong. J. Bus., 79: 671-690.
Hwang, S.W. and Y.S. Cho, 2012. Stock lending and borrowing and capital market liquidity. Korean J. Financial Eng., 11: 83-114.

Jones, M.C. and A.O. Lamont, 2002. Short-sale constraints and stock returns. J. Financial Economy, 66: 207-239.

Kim, J.S., 2010. An analysis of influence of restriction of short selling in Korea market. Capital Market Perspective, 2: 49-59.

KOFIA, Statistics of stock lending and borrowing. Korea Financial Investment Association. http://freesis.kofia.or.kr

KRX, Current situation of short selling. Korea Exchange. http://www.krx.co.kr

KSD, Performance of stock lending and borrowing. Korea Securities Depository. http://www.ksd.or.kr

Lee, E.T., 2009. An analysis of effect of short selling on stock market. Rev. Financial Risk.

Lee, J.S., K.B. Bin and K.I. Chang, 2010. A study on causal relationship of stock price and short selling. Asia-Pacific J. Financial Stud., 39: 449-489.

Nagel, S., 2005. Short sales, institutional investors and the cross-sectional of stock returns. J. Financial Economy, 78: 277-309.

Song, C.S., 2006. Motives for short selling from securities lending and stock returns. Asia-Pacific J. Financial Stud., 35: 1-37. 